\title{
Præsterne Boetius i Vilstrup.
}

Af sognepræast L. Vesten, Sulstel.

Siden Præsten Peder Rhode i 1775 udgav sine "Samlinger til Haderslev Amts Beskrivelse", der ikke just er fremragende med Hensyn til historisk Nøjagtighed, har der i de forskellige Værker, som har syslet med sønderjydsk Præstehistorie, hersket ikke ringe Forvirring, hvad Haderslev Amt angaar; særlig er det naturligvis galt fat med Forholdene $i$ det sekstende og Begyndelsen af det syttende Aarhundrede. Dr. Achelis i Haderslev og Pastor Matthiesen i Flensborg har for ikke længe siden i deres »Beiträge zur Prediger-Statistik der Propsteien Hadersleben und Törninglehn“") bragt nogen Orden i en hel Del af det Virvar, som Rhode frembragte, og som den ellers saa samvittighedsfulde Jensen forte videre $i$ sin "Kंirchliche Statistik".

Et af de Steder, hvor der hersker den storste Forvirring, nemlig Vilstrup, er de to kyndige Forskere dog gaaet uden om. Dr. Achelis har paa Forespørgsel oplyst, at Grunden var den, at der endnu var adskillige dunkle spørgsmaal, som maatte klares, for man kunde skride til at slaa noget fast med Hensyn til Vilstrup.

Det efterfølgende er da et Forsøg paa at sprede Iys over nogle af Dunkelhederne.

Den Vilstrup-Præsteliste, som Rhode og Jensen har og efter dem Mork Hansen og Nielsen, ser saaledes ud:

") Schriften deg Vereins für Schlesw.-Holst. Kirchengesch. :2. VII $499 \mathrm{ff}$. 
Laurentius Boetius Agricola 1524-27.

En Boetius, hvis Fornavn er ukendt, 1527-48.

Laurentius Boetius 1548-83.

Magister Jørgen Boysen, Kapellan 1579 eller 80, Sognepræst 1583-1603.

Niels Boysen 1603-50.

Listen er haablost forvirret. Aarstal og Navne er rystede imellem hverandre; et enkelt Navn har fordoblet sig, og et andet er falden helt ud, og det er tilmed Navnet paa den Mand, der har skrevet Slægtens Navn uudsletteligt ind i Sønderjyllands Kirkehistorie, Hertug Hans' Hofpræst, Provst over Nordstrand og Haderslev Amt, Magister Jørgen Boye, der ogsaa var Sognepræst i Vilstrup.

For Reformationen var Embedet som Sogneprest $i$ Vilstrup en Tid lang forenet med en af Kannikstillingerne ved Kollegiatkapitlet i Haderslev. C l a u s s e r c k, der døde 1482, var baade Kantor i Kapitlet og Sognepræst i Vilstrup, og begge disse Stillinger blev nu ved pavelig Provision overdraget til Gregers Smed, hvis Navn findes paa Døbebakkenet i Haderslev Kirke, og som døde 1485. Gregers smed havde i Tidens Lob samlet en hel Del Emberlsstillinger sammen; jeg er f. Eks. tilbøjelig til at tro, at han ogsaa var Sognepræst i Aastrup; la han nu døde, blev der Kapløb mellem de mange Embedsjægere, som Datiden var saa overvættes rig paa. I det væsentlige blev hans Embeder delt mellem to Brodre Jens og Mikkel Pedersen Hostrup saaledes, at Mikkel blandt andet fik Embedet som Sognepræst i Vilstrup, medens Jens tik Aastrup. Mikkel Pedersen var nu til sin Død 1521 
Prest i Vilstrup foruden at varetage den stilling som Kannik, han havde i Haderslev.*)

Da Mikkel Pedersen Hostrup var død som en gammel 80aarig Mand, strømmede Ansøgningerne atter ind til den pavelige Kurie; men da den indflydelsesrige Provst ved Kapitlet og over Barved Syssel, Johan Wulf, var blandt Ansogerne, er det rimeligt at antage, at han tog Stikket hjem.

Johan Wulf var Datidens mest berygtede Embedssluger herhjemme, og han, som andre Embedsjargere, benyttede de Stillinger, de albuede sig frem til, som en almindelig Handelsvare, der kunde vare Genstand for Køb og Salg. Det er da meget muligt, at Haderslevprovsten har solgt Vilstrup sognekald til den Laurentius Boetius med Tilnavnet Agricola, der 1524 skal have faaet Embedet, og som blev Grundlaggeren af Præstedynastiet Boysen i Vilstrup.

Allerede en halv Snes Aar tidligere træffer vi inidlertid Laurentius Boetius eller Lorents Boye, som Hertug Hans senere kalder ham paa det hjem. lige Sprog. I Aaret 1513 havde han en Ansogning hos Paven om Embedet som Sognepræst i Fjelstrup, da han mente, at dette Embede maatte være ledigt, eftersom den Peter Ankersen, der i sin Tid var bleven kaldet dertil, maatte anses for at have forspildt Kaldet ved ikke rettidigt at lacle sig prastevie. Lorents Boye, der paa det Tidspunkt ikke selv var præsteviet, fik ogsaa pavelig Provision paa Fjelstrup under den nævite Forudsatning; men derved ragede

*) Acta lontiflcum Danica IV. 
han i Proces med Peter Ankersen. En saadan Proces for de pavelige Domstole kunde være en saare lang Vej at gaa, og denne Proces blev da ogsaa først afsluttet i Aaret 1523, da Peter Ankersen maatte opgive Fjelstrup. Men da havde Lorents Boye selv for længe siden trukket sig ud af Sagen; fra Efteraaret 1515 er det en helt anden, der fører Strid med Peter Ankersen, og det ligger da nær at antage, at Boye har overdraget denne Mand sine Krav paa Sognet; det har vel varet ham for kosthar en Historie; han omtales nemlig senere $i$ en anden Ansøgning til Paven som en fattig Mand ulen, at vi dog behøver at hafte os altfor stærkt ved den Slags Udtryk i saadanne Ansøgninger.

Om Lorents Boye har faaet noget ud af sin kortvarige og stridige Forbindelse med Fjelstrup, er ikke golt at sige. Mrerkeligt er det imidlertid at se, at hans Søn, den senere Provst, havde Indtagten af Fjelstrup Sogns Kirketiende, og efter ham fik hans Enke Lov til at beholde den i en Aarrække.

I Aaret 1524, det Aar, da han skal være bleven Præst i Vilstrup, træffer vi Lorents Boye som Alterpræst i Frue Kirke i Hadlerslev; hvornaar han er bleven det, har vi, mig bekendt, ingen Oplysning om. Han havde da foruden sit forste Embede faaet overdraget en Altertjeneste til i den samme Kirke; det var et nyt Alter, som den nylig afdøde Vilstruppræst Mikkel Pedersen Hostrup inden sin Dad havde oprettet og forsynet med Gods. Boye havde allerede faaet Embedet overdraget og taget det i Besiddelse; men han sikrer sig nu pavelig Godkendelse af det, der var sket, og han fik Tilladelse til at nyde Indtagten af de to Altre saa længe, han levede.")

*) Acta p. d. VI. 
Som Præst ved Kollegiatkirken i Haderslev stod Lorents Boye i umiddelbar Forbindelse med den baade verdslig og kirkelig set mægtige Haderslevprovst Johan Wulf. Det, at han opnaaede en vistnok ikke helt regelmæssig Gunstbevisning ved selve den hellige Stol, kan kun være sket ved Provstens Anbefaling. Johan Wulf har vel da været ham venlig sindet, og hvis han, som ovenfor antydet, var den rette Sogneherre til Vilstrup, har det nok kunnet lade sig gøre at slaa en Handel af med ham saaledes, at Boye blev Præst i Vilstrup mod at betale Provsten Aftægt, og den har Johan Wulf saa kunnet hæve indtil sin Død 1541; men da Hertug Christian nogle Aar senere begyndte sit Reformationsværk i Sønderjylland, var Johan Wulfs Indflydelse uigenkaldelig forbi.

Lorents Boye var nu Præst i Vilstrup til sin Død, der dog ikke indtraf 1527, som Præstelisten siger. Dette forkerte Aarstal skyldes en Trykfejl. Øsbypræsten Magister Knud Bramsen udgav i Aaret 1569 i Wittenberg en Samling Sørgedigte, "Næniæ" kaldte han dem; det var latinske Vers, som han havde sat sammen i Anledning af en Række samtidige Mænds og Kvinders Død. Bogen var tillegnet Provsten Jørgen Boye, Lorents Boyes Søn. Der findes næppe mere noget Eksemplar af denne Bog, men den kendte Flensborgrektor 0 . Møller har 1766 meddelt Digtenes Overskrift. Et af Digtene var skrevet i Anledning af Lorents Boyes Død, og i Overskriften hed det saaledes paa Latin:

"In mortem præstantissimi viri D. Laurentii Boetii Agricole, Pastoris Wilstrupensis, qui obiit in Wilstrup anno domini 1527, 28. Septembris anno ætatis suæ 63, .. «. Dette lyder saaledes paa Dansk: 
"Ved den særdeles udmærkede Mand Hr. Laurentius Boetius Agricolas Død; han var Præst i Vilstrup og døde i Vilstrup den 28. September 1527 i sin Alders 63. Aar.« Aarstallet 1527 er en Trykfejl for 1547; men om den skyldes Knud Bramsens eller O. Møllers mangelfulde Korrekturlæsning, faar staa hen. At $1547 \mathrm{er}^{*}$ det rette Aar, fremgaar af, at der findes bevaret et Brev, som Hertug Hans den 14. September næunte Aar fra København skrev til Amtmanden i Haderslev Sivert Rantzau om at ordne en Sag mellem Lorents Boye, "pharherr zu Wilstorp" og hans Sognefolk. Hr. Lorents er rimeligvis død, inden Sagen er bleven ordnet, og den 10. Januar 1548 udnævnte Hertugen Sønnen Magister Georgius Boetius eller Jørgen Boye til hans Eftermand i Vilstrup og til tillige at være Hertugens Hofpræst.

Overleveringen vil vide, at Boysenslægten stammede fra Italien; dette er sikkert lige saa urigtigt som Aarstallet 1527. Det er et Genskin fra senere Tider, ler er falden tilbage paa den gamle Præsteslægt. Da denne ved Midten af det 17. Aarhundrede havde udtjent i Vilstrup, kom der nemlig et nyt Præstedynasti til Stedet, som holdt sig der det næste Hundrede Aar; det var Slægten Zoëga, og den anses almindeligt for at være af italiensk Herkomst. Navnet Boye og Boysen er saa godt sønderjydsk, at man ikke bør gaa udenlands for at finde dets Udspring. Jeg kan meget vel tænke mig, at Lorents Boye er den La urentius Heysacker de Hadersleben, der 1511 blev indskrevet ved Universitetet i Rostock; han vilde paa den Tid efter Knud Bramsens Aldersopgivelse have været en Mand paa 26 Aar, og da han efter Tidens Fordringer skal skrive sit Navn paa 
Latin, føjer han til Laurentius Boetius Hjemstedsbetegnelsen Agricola som en Afledning af Bynavnet Hejsagers sidste Led. At der i Hejsager paa de Tider har boet en Boysenslægt, vilde blive til Vished, i Fald man havde Lov til at antage, at den Jacobus Boethii, der 1602 blev indskrevet ved Lniversitetet $i$ Wittenberg med den lidet sigende Tilføjelse, at han var "ex agro Sleswicensi«, i Virkeligheden var en Jacob Boysen fra Hejsager i Slesvig Stift, i det den tyske Pennefører, der ikke kendte noget til Haderslevegnens Topografi, og hvis Bevidsthed bevægede sig i latinske Vendinger, har hørt Navnet "Hejsager" som et "ex agro«.")

Det faar nu være, som det vil. Men at den forste lutherske Præst i Vilstrup var en indfolt Sønderjyde, anser jeg for utvivlsomt.

Hr. Laurentius eller Lorents havde i det mindste to Sonner, Jørgen og Andreas.

Jørgen Boye, der paa Latin kaldte sig Georgius Boetius, blev 1538 indskrevet som Student ved Universitetet i Wittenberg; han er da sikkert fodt i Aarene før 1520. Han maa vel i hvert Fald være født, før Faderen blev præsteviet, da en katolsk Præst ikke kunde leve i regelret Egteskab, men et løsere Forhold var dog paa den Tid ret almindeligt mellem Præster og vakte vist ikke særlig Opsigt. Hvornaar Broderen Andreas er født, ved man ikke; men 1560 var han sammen med en Jes Raven Kirkeværge i Vilstrup, hvor Jørgen var Sognepræst. Som Kirkeværge er han kommen til at skylde Kirken en Sum Penge, hvilket fremgaar af et Uddrag af Kirkeregnskabet,

*) Om LaurentiusHeysacker og Jacob Boethii se Achelis' Gesch. Johanneums. 
som Dr. Achelis velvillig har tilstillet mig. Maaske er han dod eller er fratraadt som Kirkeværge 1565; thi i Regnskabet for 1566 ses det, at Jørgen har overtaget Forpligtelsen "wegen sines Broders, so em de Broder upgedragen hefft«; da Jørgen Boye dør 1569, hæfter i Regnskabet for 1570 "Magister Jürgen Eruen « for Gælden.

Jørgen Boye er bleven en saa kendt Mand i Sønderjyllands Kirkehistorie, og hans Levnedsløb er skildret saa udforligt flere Steder ${ }^{*}$, at det vil være overflødigt her at gaa i Enkeltheder. Det maa være nok at minde om, at han 1540-48 var Lærer ved Københavns Universitet. Det første Aar fik han kun halv Løn, var altsaa kun konstitueret Lærer; jeg henstiller, om man deraf kan slutte, at han er født 1516 og derfor først fyldte 25 Aar 1541. Straks efter Nytaar 1548 kaldte Hertug Hans ham til at være Faderens Efterfølger som Sognepræst i Vilstrup og tillige anden Hofpræst i Haderslev; 1552 blev han endvidere Hertugens Provst over Nordstrand og 1560 tillige Provst over Haderslev Amt. Hertug Hans skønnede i høj Grad paa Mester Jørgens Dygtighed og gav ham mange Beviser paa sin Bevaagenhed lige til hans Død, der indtraf den 1. Maj 1569.

Mester Jørgen blev altsaa ingen gammel Mand. Reformationsaarhundredet sled hurtig sine Folk op, og det skal da ogsaa siges, at de mange Hverv, der blev paalagt Jørgen Boye var mere end nok for en Mands Kræefter.

I Aaret 1553 havde Jørgen Boye giftet sig med Sara Meiger, en Provstedatter fra Rendsborg og

*) Bingr. Leks. II, Kirkehist. Smlg. 3. I og Rørdams Universitetshistorie I. 
Enke efter Provst Vincents Alberti i Tønder. Vi hører ikke noget om, at han tidligere har været gift. Da han døde 1569, sad hans Enke tilbage med flere mindreaarige Børn, af hvilke den ældste hed Laurentius.

Allerede nogle Aar, før Døden indtraf, har Jørger, Boye vistnok mærket, at han var ved at være opslidt, og hans Tanker gik da frem mod den Tid, da hans Hustru muligvis vilde komme til at stas alene med en Flok uforsørgede Børn. I Aaret 1565 bad han derfor Hertugen om, at en af hans Sønner maatte faa Løfte om at blive hans Eftermand i Vilstrup, saafremt han da gjorde saa god Fremgang i sine Studier, at der kunde være Haab om, at han vilde blive Kirken og sit Fædreland en nyttig Mand. Nytaarsdag 1566 svarede Hertugen paa dette Andragende med et Løfte om, at selv om Sønnerne endnu var mindreaarige ved Faderens Død, skulde Embedet blive besørget af en Kapellan under Provstens Tilsyn saa længe, til en af dem kunde overtage det. Omtrent samtidig fik Mester Jørgen et Vikarie, der hørte til Fjelstrup Kirke, og som kaldtes Hr. Sebes Len. Dette Vikarie kan næppe være det samme som den tidligere omtalte Fjelstrup Kirketiende, da Størrelsen af Indtægterne synes at have været ulige store. - Et andet Tegn paa, at Jørgen Boye begyndte at blive træt, er det, at han $\mathrm{j}$ Foraaret 1566 antager en Mand ved Navn Balthasar til Kapellan.

I Hertugens Skrivelse, hvorved en af Sønnerne faar Lofte om Vilstrup, hedder det blandt andet:

"Were es auch sache, das der Vater abgehen wurde, ehr der Sohn sein vullenkomen alter erreicht, vnd das es vmb ein jar, fünff oder sechs zu thun, so 
soll jule zugelassen sein, so lange an seiner stadt einen Caplan, der voll dem Probste gnug gelert, geschickt vind tuglich eracht, zuuordenen, bis das er der kircken selbs kan für sein vnd sein ambt der gebür vorwalten.«

Da Jorgen Boye døde, var den ældste af Sønnerne, Laurentius, formodentlig en 14-15 Aars Dreng, saa der kunde vel blive god Brug for Hertugens Naadesbevisning med Hensyn til at lade en Kapellan bestyre Embedet foreløbig, ikke blot i en 5-(; Aar, men i adskillig længere Tid. Alt dette har man ikke været kendt med, da man senere har lavet en Prxsteliste, derfor skyder man ind $\mathrm{i}$ det tomme Rum til 1583 et Navn, som intet Steds hører hjemme. Provsten Jørgen Boye er gleden ud, og da der senere kommer en yngre Jørgen Boye, erindrer man, at der foran en Jørgen Boye gik en Laurentius, hvorfor man rask væk skyder en ny Laurentius ind i Rækken, skønt han aldrig har varet der. Den ældste Søn blev nemlig ikke Faderens Eftermand, thi i saa Fald var han nok bleven der til sin Død. Vi træffer ham imidlertid senere som Sognepræst i Nørre Løgum og Præst ved Klosterkirken i Løgum; og der døde han 1619.

Men der var jo flere Sønner, og Hertugens Brev til hans Provst er naturligvis bleven opretholdt, saa naar vi i 1580 'erne træffer en G o or gi us B o e ti u s som Sognepræst i Vilstrup, kan vi med Sikkerhed gaa ud fra, at han er en yngre Søn af den gamle Jørgen Boye, og at han nu har naaet "sein vullenkomen alter", det vil sige 25 Aar. Da han siges at være bleven Sognepræst 1583, maa halı altsaa være bleven født 1558, og det kan jo passe meget vel. 
Efter det her udviklede skulde Embedet som Sogneprast i Vilstrup altsaa have staaet ledigt i 14 Aar fra 1569 til 1583, medens en Kapellan besørgede Forretningerne. Saa vidt mig bekendt har vi da heller ingen dokumenterede Vidnesbyrd om Tilstedeværelsen af en Sognepræst der i det nævnte Tidsrum. Derimod hører vi, som det var at vente, Tale om en Kapellan. Om Provst Jørgens Kapellan Balthasar har fortsat i nogen Tid som Bestyrer af Embedet, ved vi ikke; men vi ved,") at der i det nævnte Tidsrum har varet en Kapellan i Vilstrup, som hed Nicolaus Paludanus, og denne Niels Kjær, som hans danske Navn var, blev 1583 Sognepræst i Sommersted, altsaa samtidig med, at han blev overflødig i Vilstrup, fordi Jorgen Boye den yngre nu kunde overtage sir Embede. Nu hedder det sig imidlertid, at demne allerede 1579 eller 1580 er bleven "Adjunkt« i Vilstrup hos hvem? Hvis der foreligger noget skriftligt med et eller andet Indhold $i$ den Retning, er Meningen nok den, at Hertugen lover ham, at det Tilsagn om at blive Faderens Efterfølger, som han 1566 gav til en af Provstens Sønner, nu særlig skal gælde ham, da han efter i Aaret 1578 at være bleven indskrevet som Student ved Universitetet i Rostock nu gav gode Løfter om at kunne blive en nyttig Mand for Kirken og Fædrelandet.

Jørgen Boye døde 1610, maaske som et Offer for en ineget smitsom Sygdom, der det Aar hærgede Omegnen af Haderslev. Han var 22. Søndag efter Trinitatis 1607 bleven valgt til Herredsprovst, og et Vidnesbyrd om hans Provstevirksomhed har vi i den

$\because$ Kanc. Brevb. VII. T2Q. 
gamle Aastrup Kirkebog, der fortæller, at han den 2. Juli 1609 visiterede i Aastrup Kirke.

Da han døde, efterfulgtes han af $\sin$ Søn $\mathrm{N}$ i e ls B o y s e n, der var Præst til sin Død 1650. Aaret efter valgtes $\mathrm{E}$ l e r s O t t e s e n til Præst, og da han giftede sig med Formandens Enke, den gamle Niels Boysens anden Kone, kan man for saa vidt sige, at Dynastiet Boysen først udslettedes, da han døde 1659 .

Hvorefter Dynastiet Zoëga traadte til. 